\title{
PROFILE AND TREATMENT OUTCOME AMONG TUBERCULOSIS PATIENTS RETREATMENT WITH CATEGORY II REGIMEN UNDER RNTCP, SOUTH INDIA
}

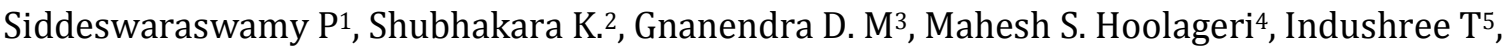 \\ Daruka K. M.6
}

\section{HOW TO CITE THIS ARTICLE:}

Siddeswaraswamy P, Shubhakara K, Gnanendra D. M, Mahesh S. Hoolageri, Indushree T, Daruka K. M. "Profile and Treatment Outcome among Tuberculosis Patients Retreatment with Category II Regimen under RNTCP, South India". Journal of Evolution of Medical and Dental Sciences 2014; Vol. 3, Issue 46, September 22; Page: 11204-11212, DOI: $10.14260 /$ jemds/2014/3461

ABSTRACT: BACKGROUND: Tuberculosis (TB) retreatments have become the matter of concern, with increase in drug resistance among failure and relapse cases of tuberculosis. Standard category II regimen is still the main TB retreatment regimen of national programs in resource limited settings. AIM: The primary objective of this study was to describe the profile and treatment outcome of TB retreatment cases treated with category II regimen. MATERIALS AND METHODS: A cross sectional study that reviewed the routinely collected data of patients with TB retreatment registered for treatment under DOTS for the period of 1 January 2011 to May 2014 was carried out at Sri Siddhartha medical college, Tumkur, Karnataka, India. RESULTS: Among 83 retreatment patients $60(71.08 \%)$ of the patients had pulmonary TB and $23(28.92 \%)$ of the patients had extra pulmonary TB. Among 60 pulmonary TB 51(85\%) were sputum positive PTB patients. Treatment after default $32(38.60 \%)$ and others $32(38.60 \%)$ were commonest reason for the TB retreatment. Majority of 'TB retreatment 'patients were aged 21-40 (40,48.20\%), predominantly males $(67.50 \%)$ than females $(32.53 \%)$ with male: female ratio is $2: 1$ shows highly statistically significant $(\mathrm{p}<0.001)$. All patients were treated with the standard RNTCP retreatment. Treatment outcome was successful (cured and treatment completed) only in $59.04 \%$ of patients, treatment after default was $18.07 \%$, treatment after failure $10.84 \%$ and death was $12.05 \%$. Treatment success was more in females, $21-40$ years age group Patients classified as 'retreatment relapse' were significantly more likely to achieve high treatment success $(81.81 \%)$ than all other types of retreatment cases. CONCLUSION: RNTCP should be strengthened to combat resurgence of retreatment cases and to improve the treatment outcome among retreatment cases.

KEYWORDS: Tuberculosis, Retreatment, RNTCP, Category II, Treatment outcome.

INTRODUCTION: According to world health organization (WHO), 'Tuberculosis retreatment' patients were previously treated tuberculosis (TB) patients have received 1 month or more of anti TB drugs in the past. They were further classified as 'relapse', 'failure', 'treatment after default (TAD)' and 'other retreatment'. ${ }^{1}$

WHO formulated Global Plan to Stop TB 2006-2015 sets a target for all the TB retreatment patients should have access to drug susceptibility testing at the time of initiation of treatment by 2015, to identify the MDR TB patients as early as possible so that appropriate treatment can be started early. ${ }^{1}$ According to WHO's Global tuberculosis report 2013, India is the highest TB burden country with statistics for 2012 giving an estimated total cases of 1.46 million cases of TB out of which 284,212 people needed TB retreatment. TB retreatment patients were relapse cases (37\%), 
other cases (34\%), treatment after default cases $(23 \%)$ and failure (6\%). Treatment success rate among the retreatment cases was 75\% in 2011.2 The currently recommended category II regimen has never been evaluated for its efficacy in randomized clinical trials or prospective cohort studies. ${ }^{3}$

The WHO recommended to add streptomycin to the four first line drugs used in category I regimen for empirical TB retreatment as per experts opinion in an era prior to the emergence of widespread multi drug resistant TB (MDRTB) and prevalent human immunodeficiency virus (HIV) infection. ${ }^{4}$ WHO guidelines recommend treatment of confirmed treatment failures and suspected multidrug resistant TB cases with region specific standardized regimens. ${ }^{5}$ But, access to drug susceptibility testing and availability of second line TB drugs very difficult in high burden countries like India. Even though inadequate retreatment regimens amplify drug resistance, still the standardized category II regimen is considered as main TB retreatment regimen of the national programs in resource limited settings. ${ }^{6,8}$

There is limited information in the published literature about which patients constitute 'retreatment' in terms of age and sex distribution, type of TB disease, sputum smear status, human immunodeficiency virus (HIV) status, diabetic status and treatment outcomes. The present study was conducted in a South Indian state to document the demographic and disease characteristics and the treatment outcomes of such 'retreatment' cases under the RNTCP, i.e., relapse, failure, TAD and other.

MATERIALS AND METHODS: STUDY SETTINGS AND DESIGN: A cross sectional analytical study was undertaken at Sri Siddhartha Medical College, Agalakote, Tumkur, and Karnataka, India from January 2011 to May 2014. All patients meeting our inclusion criteria during our study period were included in the study.

The variables documented for 'retreatment' patients were all routinely recorded on TB register, and included demographic details (age and sex), disease characteristics (disease classification, site of EPTB, HIV status Diabetes status) and treatment-related variables (Retreatment cases and treatment outcome). The data was entered into a structured proforma. The data collected was entered in Microsoft excel 2007 and analyzed using Epi Info 3.5.3. Descriptive statistics and Chi square test was used to test the association between variables of interest.

\section{Case definitions of retreatment TB patients according to WHO :}

Relapse: A TB patient who was declared cured or treatment completed by a physician, but who reports back to the health service and is now found to be sputum smear positive.

Failure: A patient whose sputum smear or culture is positive at 5 months or later during treatment. Treatment after default: A patient whose treatment was interrupted for 2 consecutive months or more and is found to be sputum smear positive.

Other: They are those who have previously been treated for TB but whose outcome after their most recent course of treatment is unknown or undocumented or Who have returned to treatment with smear-negative PTB or bacteriologically negative EPTB.

CATEGORY II REGIMEN FOR TB RETREATMENT: All the TB retreatment patients were treated with a thrice-weekly intermittent category II regimen of 8-9 months' duration under direct observation. The first 3-month intensive phase consists of 2 months of five drugs (isonaizid [H], rifampicin [R], pyrazinamide [Z], ethambutol [E] and injectable streptomycin [S)]), followed by 1 month of four 


\section{ORIGINAL ARTICLE}

drugs (HRZE). If the patient is sputum smear-positive at the end of 3 months the HRZE intensive phase is extended for another month. Irrespective of the sputum smear status at the end of the extended intensive phase, the three-drug continuation phase (HRE) is started and continued for 5 months.

\section{Definitions of Treatment outcomes according to WHO:}

Cured: A patient whose sputum smear or culture was positive at the beginning of the treatment but who was smear or culture negative in the last month of treatment and on at least one previous occasion.

Treatment completed: A patient who completed treatment but who does not have a negative sputum smear or culture result in the last month of treatment and on at least one previous occasion.

Treatment failed: A TB patient whose sputum smear or culture is positive at month 5 or later during treatment.

Died: A TB patient who dies for any reason during the course of treatment.

Defaulter: A patient whose treatment was interrupted for 2 consecutive months or more.

Treatment success: The sum of cured and treatment completed.

RESULTS: Demographic characteristics

\begin{tabular}{|c|c|}
\hline Types of TB & Number (\%) \\
\hline Pulmonary & $60(72.30)$ \\
\hline Lymph node & $06(7.20)$ \\
\hline Pleura & $06(7.20)$ \\
\hline Abdomen & $03(3.60)$ \\
\hline MEN & $03(3.60)$ \\
\hline Bone & $04(4.80)$ \\
\hline Others & $01(1.20)$ \\
\hline Total & 83 \\
\hline \multicolumn{2}{|c|}{$\begin{array}{l}\text { Table 1: Number of TB } \\
\text { retreatment cases }\end{array}$} \\
\hline
\end{tabular}

\begin{tabular}{|c|c|}
\hline TB Retreatment cases & Number (\%) \\
\hline Relapse & $11(13.3)$ \\
\hline Failure & $08(9.60)$ \\
\hline Default & $32(38.6)$ \\
\hline Others & $32(38.6)$ \\
\hline Total & 83 \\
\hline
\end{tabular}


Among 83 retreatment patients $60(72.30 \%)$ of the patients had pulmonary TB and $23(28.92$ $\%$ ) of the patients had extra pulmonary TB (Table 1). Among 60 pulmonary TB 51(85\%) were sputum positive PTB patients. Treatment after default 32(38.60\%) and others 32 (38.60\%) were commonest reason for the TB retreatment (Table 2). Majority of 'TB retreatment' patients were aged 21-40 (40,48.20\%), In this group (47.5.\%) were treatment after default patients, while (32.5\%) belonged to others category (Table 3 ).

\begin{tabular}{|c|c|c|c|c|c|}
\hline $\begin{array}{c}\text { Age } \\
\text { group }\end{array}$ & $\begin{array}{c}\text { Treatment } \\
\text { after default } \\
\mathbf{( \% )}\end{array}$ & $\begin{array}{c}\text { Treatment } \\
\text { after failure } \\
\mathbf{( \% )}\end{array}$ & $\begin{array}{c}\text { Others } \\
\mathbf{( \% )}\end{array}$ & $\begin{array}{c}\text { Relapse } \\
\mathbf{( \% )}\end{array}$ & $\begin{array}{c}\text { Total number } \\
\text { of Retreatment } \\
\text { (\%) }\end{array}$ \\
\hline$<20$ & $0(0)$ & $1(33.33)$ & $2(66.67)$ & $0(0)$ & $3(3.61)$ \\
\hline $21-40$ & $19(47.5)$ & $4(10)$ & $13(32.5)$ & $4(10)$ & $40(48.19)$ \\
\hline $41-60$ & $12(40)$ & $1(3.33)$ & $12(40)$ & $5(16.67)$ & $30(36.14)$ \\
\hline$>61$ & $1(10)$ & $2(20)$ & $5(50)$ & $2(20)$ & $10(12.04)$ \\
\hline TOTAL & $\mathbf{3 2}$ & $\mathbf{8}$ & $\mathbf{3 2}$ & $\mathbf{1 1}$ & $\mathbf{8 3}$ \\
\hline
\end{tabular}

Table 3: Age wise distribution of TB retreatment cases

Chi square: 10.89 , p value: 0.29

TB retreatment cases were predominantly males $(67.47 \%)$ than females $(32.53 \%)$ with male to female ratio is 2: 1 shows highly statistically significant $(\mathrm{p}<0.001)$ (Table 4$)$. HIV status and diabetic status was known, 4 (4.8\%) were HIV-positive and 17(20.5\%) were diabetic. All patients were treated with the standard RNTCP retreatment. Treatment outcome was successful (cured and treatment completed) only in $59.04 \%$ of patients, treatment after default was $18.07 \%$, treatment after failure $10.84 \%$ and death was $12.05 \%$.

\begin{tabular}{|c|c|c|c|c|c|}
\hline Gender & $\begin{array}{c}\text { Treatment } \\
\text { after } \\
\text { default } \\
\mathbf{( \% )}\end{array}$ & $\begin{array}{c}\text { Treatment } \\
\text { after } \\
\text { failure (\%) }\end{array}$ & $\begin{array}{c}\text { Others } \\
\mathbf{( \% )}\end{array}$ & $\begin{array}{c}\text { Relapse } \\
\mathbf{( \% )}\end{array}$ & $\begin{array}{c}\text { Total } \\
\text { number of } \\
\text { Retreatment } \\
\mathbf{( \% )}\end{array}$ \\
\hline Female & $2(7.40)$ & $4(14.81)$ & $16(59.25)$ & $5(18.51)$ & $27(32.53)$ \\
\hline Male & $30(53.57)$ & $4(7.14)$ & $16(28.57)$ & $6(10.71)$ & $56(67.47)$ \\
\hline TOTAL & $\mathbf{3 2}$ & $\mathbf{8}$ & $\mathbf{3 2}$ & $\mathbf{1 1}$ & $\mathbf{8 3}$ \\
\hline \multicolumn{7}{r}{ Table 4: Gender wise distribution of TB Retreatment cases } \\
\hline
\end{tabular}

Chi square: $16.46, \mathrm{p}$ value: 0.001

\begin{tabular}{|c|c|}
\hline Treatment outcome & Number (\%) \\
\hline Cure & $24(28.92)$ \\
\hline Treatment Completed & $25(30.12)$ \\
\hline Treatment after Default & $15(18.07)$ \\
\hline Treatment after Failure & $09(10.84)$ \\
\hline Death & $10(12.05)$ \\
\hline
\end{tabular}

Table 5: Treatment outcome among TB retreatment cases 


\begin{tabular}{|c|c|c|c|c|c|c|c|}
\hline \multirow[b]{2}{*}{ Characteristic } & \multicolumn{5}{|c|}{ Treatment outcome } & \multirow[b]{2}{*}{$\begin{array}{c}\text { Chi } \\
\text { square } \\
\text { value }\end{array}$} & \multirow[b]{2}{*}{$\begin{array}{c}\mathbf{p} \\
\text { value }\end{array}$} \\
\hline & $\begin{array}{c}\text { Treatment } \\
\text { completed } \\
\text { (\%) }\end{array}$ & Cure (\%) & $\begin{array}{c}\text { Treatment } \\
\text { after } \\
\text { default } \\
\text { (\%) }\end{array}$ & $\begin{array}{c}\text { Death } \\
\text { (\%) }\end{array}$ & $\begin{array}{c}\text { Treatment } \\
\text { after } \\
\text { failure } \\
(\%)\end{array}$ & & \\
\hline \multicolumn{8}{|c|}{ Age group } \\
\hline$<20$ & $2(66.66)$ & $0(0)$ & $0(0)$ & $0(0)$ & $1(33.34)$ & \multirow{4}{*}{12.14} & \multirow{4}{*}{0.43} \\
\hline $21-40$ & $10(25)$ & $15(37.5)$ & $8(20)$ & $5(12.50)$ & $2(5)$ & & \\
\hline $41-60$ & $8(26.66)$ & $7(23.33)$ & $4(13.33)$ & $5(16.67)$ & $6(20)$ & & \\
\hline$>60$ & $3(30)$ & $3(30)$ & $3(30)$ & $0(0)$ & $1(0)$ & & \\
\hline \multicolumn{8}{|c|}{ Gender } \\
\hline Female & $12(44.44)$ & $\begin{array}{c}10(37.03 \\
)\end{array}$ & $1(3.70)$ & $3(11.11)$ & $1(3.70)$ & \multirow{2}{*}{11.59} & \multirow{2}{*}{0.02} \\
\hline Male & $11(19.64)$ & $\begin{array}{c}15(26.78 \\
)\end{array}$ & $14(25)$ & $7(12.5)$ & $9(16.07)$ & & \\
\hline \multicolumn{8}{|c|}{ RELIGION } \\
\hline Hindu & $22(29.33)$ & $\begin{array}{c}23(30.66 \\
)\end{array}$ & 13(17.33) & $8(10.66)$ & $9(12)$ & \multirow{2}{*}{2.28} & \multirow{2}{*}{0.68} \\
\hline Muslim & $1(12.5)$ & $2(25)$ & $2(25)$ & $2(25)$ & $1(12.5)$ & & \\
\hline \multicolumn{8}{|c|}{ HIV status } \\
\hline Non-Reactive & $21(26.58)$ & $\begin{array}{c}23(29.11 \\
)\end{array}$ & $15(18.98)$ & $10(12.65)$ & $10(12.65)$ & \multirow[t]{2}{*}{3.07} & \multirow[t]{2}{*}{0.54} \\
\hline Reactive & $2(50)$ & $2(50)$ & $0(0)$ & $0(0)$ & $0(0)$ & & \\
\hline \multicolumn{8}{|c|}{ DIABETES } \\
\hline Non diabetic & $18(27.27)$ & 21(31.81 & 13(19.69) & $6(9.09)$ & $8(12.12)$ & \multirow{2}{*}{3.85} & \multirow[t]{2}{*}{0.42} \\
\hline Diabetic & $5(29.41)$ & $5(29.41)$ & $1(5.88)$ & $4(23.52)$ & $2(11.76)$ & & \\
\hline
\end{tabular}

Association between various characteristic and treatment outcome :

The association between demographic and clinical characteristics and treatment outcomes is shown in Table 6. Treatment success (cure and treatment completed) of $62.5 \%$ observed in 21-40 years age group. Treatment success was more in females $(81.47 \%)$ than males $(46.42 \%)$. HIV and diabetic patients had adverse treatment outcome.

\section{Comparison of treatment outcomes with different types of retreatment TB cases :}

The treatment outcomes were compared between different types of retreatment patients using data available at the DOTS center (Table 7). Patients classified as 'retreatment relapse' were significantly more likely to achieve treatment success $(81.81 \%)$ than all other types of retreatment cases. 


\begin{tabular}{|l|c|c|c|c|c|c|}
\hline $\begin{array}{c}\text { TB } \\
\text { Retreatment } \\
\text { cases }\end{array}$ & $\begin{array}{c}\text { Treatment } \\
\text { completed } \\
\mathbf{( \% )}\end{array}$ & Cure (\%) & $\begin{array}{c}\text { Treatment } \\
\text { after } \\
\text { default } \\
\mathbf{( \% )}\end{array}$ & $\begin{array}{c}\text { Death } \\
\mathbf{( \% )}\end{array}$ & $\begin{array}{c}\text { Treatment } \\
\text { after } \\
\text { failure } \\
\mathbf{( \% )}\end{array}$ & TOTAL \\
\hline $\begin{array}{l}\text { Treatment } \\
\text { after default }\end{array}$ & $1(3.12)$ & $11(34.37)$ & $7(21.87)$ & $5(15.62)$ & $8(25)$ & 32 \\
\hline $\begin{array}{l}\text { Treatment } \\
\text { after failure }\end{array}$ & $0(0)$ & $5(62.50)$ & $1(12.50)$ & $1(12.50)$ & $1(12.50)$ & 8 \\
\hline Others & $22(68.75)$ & $0(0)$ & $6(18.75)$ & $4(12.50)$ & $0(0)$ & 32 \\
\hline Relapse & $0(0)$ & $9(81.81)$ & $1(9.09)$ & $0(0)$ & $1(9.09)$ & 11 \\
\hline \multicolumn{1}{|c|}{ T0TAL } & $\mathbf{2 3}$ & $\mathbf{2 5}$ & $\mathbf{1 5}$ & $\mathbf{1 0}$ & $\mathbf{1 0}$ & $\mathbf{8 3}$ \\
\hline
\end{tabular}

Table 7: Comparison of treatment outcomes with different types of retreatment TB cases

Chi square: $65.02 \mathrm{p}$ value: 0.001

DISCUSSION: TB retreatment with category II regimen has been a cause of a much debate, in the era of multidrug resistant TB. It has been controversial whether to continue or eliminate category II regimen in TB retreatment. The present study shows the treatment outcome of TB retreatment cases with the category II regimen. In the present study, the rate of relapse, treatment failure and treatment after default cases and others were $13.3 \%, 9.6 \%$ and $38.6 \%$ and $38.6 \%$ respectively.

We found that the major group who had received previous RNTCP treatment was treatment after default and others cases, while in a study done by Jha et $\mathrm{al}^{9}, 33.0 \%$ were relapse patients, 37.6\% were treatment after default, 20.5\% were other patients, and $8.9 \%$ were failure cases. In the present study on the TB retreatment patients, maximum patients belonged to the age group of 21-40 years $(48.19 \%)$, treatment after default $(47.5 \%)$ followed by others $(32.5 \%)$ were commonest groups in this age group, who are young and working individuals, highlighting the socio-economic burden of TB retreatment.

Similar reports of higher incidence of TB retreatment in younger individuals are reported by other study as well. ${ }^{10}$ Males 56(67.47\%) outnumbered females $27(32.53 \%)$ in this study with Male to Female ratio of 2: 1 . Similar trends have been observed by Jha et al. ${ }^{9}$, with $1198(70 \%)$ males and $514(30 \%)$ females in the study on retreatment TB cases and Sandeep SS et al ${ }^{10}$ observed Males 348(63.9\%) outnumbered females 197(36.1\%) in this study with Male to Female ratio of 1.76: 1.

Treatment after default (53\%) is more common in males. Young age, male appears to be the risk factors for treatment after default, Hence, identifying patient characteristics that confer a higher risk of treatment after default, relapse, failure from primary TB treatment may help to plan and implement country specific prevention strategies aiming to reduce the need for the retreatment, resulting in cost savings and diminished morbidity and transmission.

Our study shows conflicting results with treatment outcome. It has shown treatment success (cure and treatment completed) of 59.04\% among the TB retreatment cases which is low compared to national data, ${ }^{2}$ which shows treatment success of $75 \%$. Our study shows higher treatment after default rate of $18.07 \%$, failure rate of $10.84 \%$ and death rate of $12.05 \%$. The chances of high treatment after default and failure rate increases the morbidity and mortality of tuberculosis, causing 
to be a matter of grave concern in public health. This indicates the need to manage and measures should be taken to reduce the number of treatment after default and failures. Association of treatment outcome by various characteristics has shown treatment success was better in the age group of 21-40 years group (62.5\%) and in females (81.47\%) compared males (46.42\%).

We also studied the association of treatment outcome by subcategory of TB retreatment cases. It shows cure rate was highest in the relapse group (81.81\%) while in the failure group was $(62.50 \%)$ which is comparable to RNTCP status report $2012^{11}$ which shows cure rate in relapse (75\%) and cure rate in failure (57\%). But cure rate in default group was (34.37\%) which was less compared to $68 \%$ in RNTCP status report 2012.

Treatment completion rate was highest (68.75\%) in the `Other' group of patients. Default rate was frequent in patients with a prior history default group (21.67\%) during previous treatment, and failure rate was also highest in patients with previous treatment default (25\%). Although treatment regimen is same in all retreatment groups ${ }^{12}$, but findings of our study address the need for different management strategies for different retreatment groups.6,13

For example, treatment failure is commonly due to drug resistance, while relapse may be due to poor economic or health condition. Treatment after default patients may require intensified case management and education rather than more intensive treatment. Our study shows patients who had relapse after previous treatment with a category I regimen were more likely to be cured with the Category II retreatment regimen.

Patients who failed with the Category I treatment had a high chance of failing and also defaulting on the Category II retreatment regimen, and patients who default from a first antituberculosis treatment regimen had a high risk of also defaulting and failing from the Category II retreatment regimen.

CONCLUSION: RNTCP should be strengthened to combat resurgence of retreatment cases and to improve the treatment outcome among retreatment cases. Periodic re-orientation training of doctors and DOTS providers, ensuring proper supervision, review of performance and timely feedback regarding performance of unit can be undertaken at the present moment for improvement of performance. Access to DST and to the second line TB drugs with the Prompt early diagnosis of MDR TB and treatment with second-line drugs improves the chance of cure and prevents the development of failure cases and spread of further resistance.

\section{REFERENCES:}

1. World Health Organization. Treatment of Tuberculosis Guidelines.4th ed. World Health Organization; 2010. Available from:

http://www.whqlibdoc.who.int/publications/2010/ 9789241547833_eng.pdf. [Last accessed on 2014 August 26].

2. World Health Organization. Tuberculosis: Global tuberculosis report 2013. Available from: http: //www.who.int/tb/publications/global_report/gtbr13_annex_2_country_profiles.pdf. [Last accessed on 2014 August 26]

3. Menzies D, Benedetti A, Paydar A, Royce S, Madhukar P, Burman W,et al. Standardized treatment of active tuberculosis in patients with previous treatment and/or with monoresistance to isoniazid: Asystematic review and meta-analysis. PLoS Med 2009; 6: e1000150. 
4. Rouillon A. The Mutual Assistance Programme of the IUATLD.Development, contribution and significance. Bull Int Union Tuberc Lung Dis 1991; 66: 159-72.

5. World Health Organization (WHO). Guidelines for the Programmatic Management of DrugResistant Tuberculosis. Geneva, Switzerland: World Health Organization (WHO); 2010.

6. Espinal MA. Time to abandon the standard retreatment regimen with first-line drugs for failures of standard treatment. Int J Tuberc Lung Dis 2003; 7: 607-8.

7. Matthys F, Rigouts L, Sizaire V, Vezhnina N, Lecoq M, Golubeva V,et al. Outcomes after chemotherapy with WHO category II regimen in a population with high prevalence of drug resistant tuberculosis. PLoS One 2009; 4: e7954.

8. Quy HT, Lan NT, Borg dorff MW, Grosset J, Linh PD, Tung LB, et al. Drug resistance among failure and relapse cases of tuberculosis: Is the standard re-treatment regimen adequate? Int J Tuberc Lung Dis 2003; 7: 631-6.

9. Jha UM, Satyanarayana S, Dewan PK, Chadha S, Wares F, et al. Risk factors for treatment default among re-treatment tuberculosis patients in India, 2006. PLoS ONE. 2010; 5(1): e8873. doi: 10.1371/journal.pone.0008873.

10. Sandeep S S, Naveen K G, Dinesh K, Janmeja A K, Treatment Outcome Among the Retreatment Tuberculosis (TB) Patients under RNTCP in Chandigarh, India Journal of Clinical and Diagnostic Research. 2014; 8(2): 53-56.

11. 11. Central TB Division, Directorate General of Health Services, Ministry of Health and Family Welfare, Nirman Bhawan, New Delhi. TB India 2012, RNTCP Status Report; 2012: 111.

12. World Health Organization. Treatment of Tuberculosis: Guidelines for National Programmes. WHO/CDS/TB/2003.313. 3rd ed. Geneva, Switzerland: WHO; 2003.

13. Zignol M, Wright A, Jaramillo E, Nunn P, Raviglione MC. Patients with previously treated tuberculosis no longer neglected. Clin Infect Dis 2007; 44: 61-4. 


\section{ORIGINAL ARTICLE}

\section{AUTHORS:}

1. Siddeswaraswamy P.

2. Shubhakara K.

3. Gnanendra D. M.

4. Mahesh S. Hoolageri

5. Indushree $\mathrm{T}$.

6. Daruka K. M.

\section{PARTICULARS OF CONTRIBUTORS:}

1. Assistant Professor, Department of General medicine, Sri Siddhartha Medical College, Agalakote, Tumkur, Karnataka State, India.

2. Assistant Professor, Department of General medicine, Sri Siddhartha Medical College, Agalakote, Tumkur, Karnataka State, India.

3. Assistant Professor, Department of General Medicine, Sri Siddhartha Medical College, Agalakote, Tumkur, Karnataka State, India.

4. Assistant Professor, Department of Community Medicine, Sri Siddhartha Medical College, Agalakote, Tumkur, Karnataka State, India.
5. Resident, Department of General Medicine, Sri Siddhartha Medical College, Agalakote, Tumkur, Karnataka State, India.

6. Associate Professor, Department of General Medicine, Sri Siddhartha Medical College, Agalakote, Tumkur, Karnataka State, India.

\section{NAME ADDRESS EMAIL ID OF THE CORRESPONDING AUTHOR:}

Dr. Siddeswaraswamy P,

Assistant Professor,

Department of General Medicine,

Sri Siddhartha Medical College,

Agalakote, Tumkur,

Karnataka, India

Email: swamyp26@gmail.com

Date of Submission: 19/08/2014.

Date of Peer Review: 20/08/2014.

Date of Acceptance: 15/09/2014.

Date of Publishing: 20/09/2014. 